\title{
STUDENTS' EXPECTATIONS TOWARDS INSTRUCTOR ROLE IN ONLINE LEARNING
}

\author{
Rijanto Purbojo, Gemala Garibaldi \\ Pelita Harapan University, Swiss German University
}

\begin{abstract}
Adapting with the characteristics of students from Millennial generation requires a more flexible type of learning approach such as online learning. Recent studies have also showed that students perceive online courses to be most convenient compared to face to face (F2F) course which are seen to be more conducive to their learning style. Online learning intructors need to delve into the list of expectations from students in order to prepare and set up the right instruments and means in creating an effective online learning environment. Descriptive research study is conducted on approximately 254 university students to gather information and offer insights into what are expected from instructors in relation to online learning. The results are beneficial in creating a more meaningful learning experience for students and possess the knowledge and skills aligned with the $21^{\text {st }}$ century learner outcomes. It will also assist the university in constructing the right infrastructure to support the learners' needs and expectations. The finding will also promote a better means to promote student-teacher and student-student interaction as well as striving for social, cognitive, and teaching presence. To conclude, several particular roles can be further elaborated as recommendations, for instance, instructors may design instructor induction program or technological based learning guidance to meet students' expectation.
\end{abstract}

Keywords: online learning, student expectation, instructor role, Millennials, $21^{\text {st }}$ century learner

\section{INTRODUCTION}

In the recent years, there has been an immense growth and use of ICT (Information

\& Communication Technology) in the education sector by combining traditional classroom methods and online digital media. With a more modern and flexible approach, learners are encouraged to be more active which place them in the driver's seat. The student-centered and self-directed approach also indicates a shift in the roles of instructors where they no longer call the shots on conducting classroom activities. Within the context of this online environment, the traditional roles of teacher and learner became reciprocal and symbiotic (Barber \& King, 2016). In other words, instructors should not mistake the convenience and flexibility of 
online learning as less demanding than teaching traditional classroom. Instructors need to be well informed, well trained, and armed with sound knowledge and skills necessary to manage online learning environment. For one, instructors need to integrate the content of subject being taught supported by the knowledge of technology itself and select the pedagogy that suits the students' characteristics as a whole incorporated framework of teaching. The pedagogy itself must be shaped in ways that students can co-develop the learning goals and work within challenging and supportive environments to develop the "new basics" of 21 c skills (Barber \& King, 2016). To address this issue, Mishra and Koehler (2006) came up with a powerful framework by conceptualizing the complex relationships between Content, Pedagogical and Technological Knowledge (TPACK), and how this knowledge can be used in teaching and learning (Benson \& Ward, 2013). This model suggests that in order to enhance students' learning experience, technology should be implemented in delivering the subject and it should also support the pedagogy. Consequently, a state of the art learning infrastructure alone is not enough. Instructors are facing the challenges in the adoption of technology knowledge within online learning environment and ensure that the end result does benefit the students.

With the high demands in producing skillful and better prepared graduates, the students' expectations should also be taken into account. This signifies that universities should plan ahead to ensure the courses meet the standards of student expectation. Additionally, there is now a need to focus on other dimensions of learning, such as lifelong, social and relationship skills, cultural sensitivity to other life perspectives or ethnicities, and digital skills, among others (Pellegrino \& Hilton, 2013; in Gómez-Rey, Barbera, \& Fernández-Navarro, 2018). Every $21^{\text {st }}$ century skills implementation requires the development of key academic subject knowledge and understanding among all students, referring to those who can think critically and communicate effectively must build on a base of key academic subject knowledge (Chu, Reynolds, Tavares, Notari, \& Lee, 2016; Systems, 2016). Suggestively, the contents that are being delivered have to offer more implementation and offer values on how the subject itself can be applied in real life-work situation. Thus, students expect to be driven and flourish as a life-long learner with sufficient foundation of theoretical knowledge, a set of management and innovation skills combined with the relevant competencies, and digital literacy in order to survive in the workplace.

With that being said, instructors are now expected to carry out multiple roles in leading students' activities within online learning environment. However, to maximize the output of learning itself, instructors should also identify the characters of $21^{\text {st }}$ century learners prior to implementing their expected roles. Members of the Millennial generation occupy today's classroom as students (Alexander, 2012). As most current instructors are most likely to come from Generation X, it has even become more challenging for to establish a connection and understanding with their students, specifically for those who fail to acknowledge the importance of 'upgrading' 
their skills in the digital literacy context. Additionally, Howe \& Strauss (2012) mentioned that educators should understand their characteristics as they try and connect with their Millennial students, where according to generational traits these students strive to learn if teaching strategies for their needs (Alexander, 2012). It is also stated that traits of millennial students include "digital literacy, experiential and engaging learning, interactivity and collaboration, and immediacy and connectivity" (Skiba \& Barton, 2006; in Alexander, 2012). Oblinger \& Oblinger (2015) state that Millennials do not think "in terms of technology; they think in terms of the activity the technology enables" (Alexander, 2012). Hence, instructors are now dealing with a tech-savvy generation, where failure to adapt with students' characters and needs, will enlarge the discrepancy between these two different generations even more, as it is most likely to occur within this setting. For that reason, it is important to understand how Millennials students perceive technology to offer insights of their expectations in online learning, not just the technology as a learning infrastructure it self but also the kinds of competencies that instructors expected to master in teaching and managing students in online learning environment.

Based on the explanation above, it also signifies a critical role for instructors to act as support systems for their students. In accordance with technology, Millennial students require their instructors to be innovative in order to engage learners through applicable skills and knowledge, appropriate technologies, and real-world connections to make learning relevant, personalized, and engaging (Chu et al., 2016). On that note, 21st century standards, assessments, curriculum, instruction, professional development and learning environments must be aligned to produce a support system that produces 21st century outcomes for today's students (The Partnership For 21St Century Skills, 2009). This indicates that aside from technological domain, instructors are also required to act as a designer of the learning content and create engagement among student-instructor and reinforce student-student interaction within online environment. It also requires instructors to apply various learning approaches, providing guidance and feedbacks while motivating and monitoring students at the same time.

From the ongoing discussion above, this study focus on investigating the university students' expectation towards instructor roles in online learning environment and determine which instructor role(s) that university students expected the most. The study also compares and identifies whether different expectations exist between university students who are regularly exposed to using online learning with the ones who are less/ not yet exposed to online learning. Moreover, the result also offers insight for university instructors as a guideline in evaluating their roles in online learning. 


\section{LITERATURE REVIEW}

Online learning environments can be categorized into three central groups, fully web based, blended or hybrid format, and traditional courses using web based supplements (Gilbert, 2015). Unlike face-to-face method, online learning requires the instructor to perform additional set of skills. This means the introduction of e-learning can no longer be business as usual for the instructor, as there is a need to evaluate and adapt the content, rethink teaching and learning styles, re-evaluate one's aptitude and attitude towards technology, as well as other human, technical and educational factors (Singh, O'Donoghue \& Worton, 2005; Seymour \& Serumola, 2016; in Mncube, Dube, \& Ngulube, 2017). This implies that educators are left with no options but to learn more competencies and have the expertise in teaching online. Hence, instructors should be properly trained (Mncube et. al, 2017).

The majority of current university students are Millennial generation and they are comfortable with technology. However, it does not imply that these students will also effortlessly as accepting when implementing technology as part of their learning activity. Since most current instructors are from Generation X, this indicates that instructors are dealing with a generation of sophisticated technology users which creates discrepancy among generation and this discrepancy in differing technology and experiences has to be narrowed (Chitanana, 2014; in Mncube et al., 2017). Moreover, research also shows that there are always underlying factors that impact on user acceptance processes that will enable Millennials to engage with e-learning technologies (Abbad, Morris \& Nahlik, 2009; Tarhini, Hone, Liu \& Tarhini, 2017; in Mncube et al., 2017). Millennial students prefer a learning environment that utilizes technology that provides a high level of interactivity (Selwyn, 2007) and enables them to measure progress and achieve goals (Jones-Dwyer and Pospisil 2005; Sweeney 2006; in Rodriguez \& Honeycutt, 2014). Millennials demand a new learning paradigm (Skiba \& Barton, 2006) and their learner characteristics includes "digital literacy, experiential and engaging learning, interactivity and collaboration, and immediacy and connectivity" (Howe \& Strauss, 2000; in Skiba \& Barton, 2006). Also, the use of technology in today's classroom that enables convenience, customization, and collaboration is greatly received by millennial students (Oblinger \& Oblinger, 2005; Roberts, 2005).

Numerous researches have been conducted to define the skills required for $21^{\text {st }}$ century students. Many of these authors concur that these skills include the development of creativity, self-motivation, innovation, problem- solving and collaboration skills (McNeill, Gosper \& Xu, 2012; Voogt, Erstad, Dede \& Mishra, 2013; Kaufman, 2013 in Barber \& King, 2016). To address this, one framework has been widely used to point out the expected results once they have finished their education. A model known as The Framework for $21^{\text {st }}$ Century Learning describes the skills, knowledge and expertise students must master to succeed in work and life; 
it is a blend of content knowledge, specific skills, expertise and literacies (The Partnership For $21^{\text {St }}$ Century Skills, 2009) (see Figure 1).

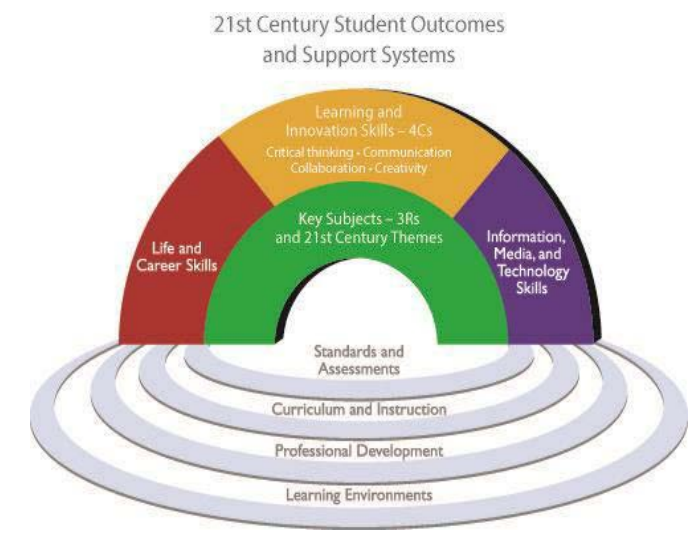

Figure 1. $21^{\text {st }}$ Century Student Outcomes and Support Systems

The model depicts that schools must promote an understanding of academic content at much higher levels. The framework also suggests that one of the learning environments of $21^{\text {st }}$ century students should support expanded community and international involvement in learning, both face-to-face and online. Professional development and learning environments must be aligned to produce a support system that produces $21^{\text {st }}$ century outcomes for today's students. This is another point highlighted that with said outcomes, students would want to have assurance that they have invested their education fee, and in return will be facilitated by experienced, competent, and well-trained instructors during their university years, and it includes online learning.

There are numerous researches which attempt to define the roles of instructors within online learning settings. In addition to facilitating learning, the instructors role often includes designing curricular materials, managing the learning process and environment, and providing a social presence to overcome a feeling of disconnect or isolation among students (Dennen, Darabi, \& Smith, 2007; Richardson et al., 2015; in Richardson, Besser, Koehler, Lim, \& Strait, 2016). Alvarez et.al (2009) proposed five roles that could be identified with regards to the tasks carried out by university teachers in online environments: (1) Designer/planning role which includes instructor behavior related to course planning, organizing, leading and controlling; (2) Social role where instructors perform the tasks of influencing students' relationships with the instructor and with other students; (3) Cognitive role deals with mental processes pertaining to perception, learning, information storage, memory, thinking and problem-solving; (4) Technological domain relates to knowledge of support services, multimedia knowledge, basic technology knowledge, technological access knowledge and software skills, and data analysis skills, and (5) Managerial domain which is a group of competencies that allow the teacher to develop and adapt the planned actions and also integrate transversally into any of the teacher's roles, such 
as: responding to expectations, motivation and learning needs; administering the online classroom; managing spaces and channels of communication - in other words, supervising and tailoring the process in progress and online.

Given the imperative for universities to attract students in a globalised market, and demonstrate the value of their online courses, coupled with the growing perspective of students-as-consumers, it could be argued universities should prioritise strategies that ensure their courses meet the standards students expect (Henry, 2018). It can be said that once students' expectations are met, it will also affect their satisfaction towards learning. Some of the factors that affect the usage and satisfaction of elearning technologies in most universities in developing countries include the instructional efforts, technological infrastructure, the high cost of technology, selfcompetencies, satisfaction, methodology, management support, training, resource accessibility and availability, the culture of education and learning styles, intellectual investment, the design of assistive tools, and global business (Ghazal, Aldowah, Umar, \& Bervell, 2018). It shows that when all those contributing factors are applied, students will know how to set goals, what is needed to achieve those goals, and how to actually attain these goals. Therefore, in order for students to self-regulate and direct their own behaviors, they must also be motivated or driven to attain goals (Kitsantas \& Dabbagh, 2010, in Dabbagh \& Kitsantas, 2012). When lecturers succeeded in assisting students in their self-regulated learning, lecturers are fostering the skills and motivation to lead them in becoming $21^{\text {st }}$ century expected graduate outcomes. By using the same model of the role of instructor, a preliminary study that interviewed 10 university lecturers was done by Purbojo (2018), indicating several challenges from the teacher perspective. One, there seemed to be some difficulties in developing and adapting planned (teaching) actions during the application of managerial domain role and also lack of awareness that the instructor needs technological competencies, especially in responding to student's expectation, motivation and learning needs. Second, as the implication of the first challenge, the instructors were also unaware of their roles in managing and supervising, and tailoring the learning progress by applying their cognitive and social role.

\section{METHOD}

This research uses Descriptive Research Design and Quantitative data collection and analysis which aims to explore the student's expectation towards instructor in online learning environment. The questionnaire used in this study was designed based on the theoretical construct of the instructor roles in blended learning (Alvarez, Guasch, and Espasa, 2009; Purbojo, 2018). It consists of 5 dimensions of the roles of instructor in blended learning, as depicted in Table 1. 
Table 1 Number of Dimensions and items of Role of Instructor in online learning environment

\begin{tabular}{lll}
\hline No & Dimension & Items \\
\hline $\mathbf{1}$ & Designer/Planning Role & 7 \\
\hline $\mathbf{2}$ & Social Role & 11 \\
\hline $\mathbf{3}$ & Cognitive Role & 7 \\
\hline $\mathbf{4}$ & Technological Domain & 6 \\
\hline $\mathbf{5}$ & Managerial domain & 4 \\
\hline & Total & 35 \\
\hline
\end{tabular}

Data collection was conducted in 10 days using an online survey system (www.limesurvey.org) in 2 private universities (University $U$ and University $S$ ) in Tangerang area. Three hundred fifty students from non-science study programs were requested to participate voluntarily. Despite the limitation of the sampling distribution, we are optimistic that the opportunity of having attractive online learning in the future is fairly high in non-science study programs due to the less requirement of laboratory sessions. Thus, it would be wise to model the expectation from the students from these departments.

University $U$ has launched its distance learning program for a bachelor degree since 2017, with a number of 190 students joining distance learning program. They also apply blended learning strategy regularly in other study programs. University S has had the policy and initiatives to utilize a blended learning strategy; however, it has a very limited to none activities among lecturers and students regarding this matter.

The data was compiled and analysed using SPSS 23 statistic software package to extract descriptive information and comparison analysis among categorical data. Factor analysis was also applied to yield latent factors in order to ground the theoretical construct of student expectations toward instructor roles in online learning.

\section{RESULT AND DISCUSSION}

\section{Demographic data}

A number of 270 completed questionnaires were returned. However, 16 respondents were found to unauthentic answers and therefore must be removed prior to the analysis. The total respondents of University $U$ are 195 and the respondents of University S are 59 students. 
Table 2 Demographic Data Univ U

\begin{tabular}{lllll}
\hline Data & Type & Frequency & Percent \\
\hline \multirow{3}{*}{ Gender } & Female & 140 & 71.8 \\
\cline { 2 - 5 } & Male & 55 & 28.2 \\
\cline { 2 - 4 } & Total & 195 & 100.0 \\
\hline \multirow{4}{*}{ Age } & Below 20 & 84 & 43.1 \\
\cline { 2 - 4 } & $21-25$ & 74 & 37.9 \\
\cline { 2 - 4 } & $26-30$ & 12 & 6.2 \\
\cline { 2 - 4 } & $31-36$ & 4 & 2.1 \\
\cline { 2 - 4 } & Above 36 & 21 & 10.8 \\
\cline { 2 - 4 } & Total & 195 & 100.0 \\
\hline \multirow{2}{*}{ Cohort } & 2014 & 3 & 1.5 \\
\cline { 2 - 4 } & 2015 & 43 & 22.1 \\
\cline { 2 - 4 } & 2016 & 29 & 14.9 \\
\cline { 2 - 4 } & 2017 & 70 & 35.9 \\
\cline { 2 - 4 } & 2018 & 50 & 25.6 \\
\hline & Total & 195 & 100.0 \\
\hline
\end{tabular}

From this cohort grouping we assume that there are at least 50 (25.6\%) students who have been exposed to online learning scenarios for less than a year and about $70(35.9 \%)$ students who have been exposed to the same scenario for about 2 years. Additionally, there are 91(46\%) distance learning students among these cohorts. From this composition we assume that their answer would represent, both, distance learning and blended learning scenario during studying.

Table 3 Demographic Data Univ S

\begin{tabular}{lllll}
\hline Data & Type & Frequency & Percent \\
\hline \multirow{2}{*}{ Gender } & Female & 35 & 59.3 \\
\cline { 2 - 4 } & Male & 24 & 40.7 \\
\cline { 2 - 4 } Age & Total & Below 20 & 59 & 100.0 \\
\cline { 2 - 4 } & $21-25$ & 38 & 64.4 \\
\cline { 2 - 4 } & Total & 21 & 35.6 \\
\hline \multirow{2}{*}{ Cohort } & 2014 & 59 & 100.0 \\
\cline { 2 - 4 } Year & 2015 & 3 & 5.1 \\
\cline { 2 - 4 } & 2016 & 17 & 28.8 \\
\cline { 2 - 4 } & 2017 & 28 & 47.5 \\
\cline { 2 - 4 } & 2018 & 10 & 1.7 \\
\cline { 2 - 4 } & Total & 59 & 100.0 \\
\hline
\end{tabular}

Although we have seen variations of students' cohort year, we are aware that this university has not yet implemented either distance learning or blended learning scenarios in their day to day teaching practices. No information is provided to specify whether University $S$ has implemented learning management in their academic policy. By using this student group we expect to discover a different pattern of answers on students' expectation toward the roles of instructors in online learning. 
Table 4 Mean Scores Comparison between University $U$ and University S (per dimension)

\begin{tabular}{lll|l|l|l} 
& Univ & N & Mean & Std. Deviation & Std. Error Mean \\
\cline { 2 - 6 } DesignRole & Univ U & 195 & 4.2007 & .48856 & .03499 \\
\cline { 2 - 6 } & Univ S & 59 & 4.0993 & .45891 & .05974 \\
\hline \multirow{2}{*}{ SocialRole } & Univ U & 195 & 4.1921 & .47863 & .03428 \\
\cline { 2 - 6 } CognitiveRole & Univ S & 59 & 4.0740 & .52182 & .06793 \\
\hline \multirow{2}{*}{ TechnoDomain } & Univ U & 195 & 4.1700 & .51610 & .03696 \\
\hline & Univ S & 59 & 4.0605 & .53400 & .06952 \\
\hline \multirow{2}{*}{ ManagerialRole } & Univ U & 195 & 4.2402 & .52706 & .03774 \\
\hline & Univ S & 59 & 4.1328 & .60393 & .07862 \\
\hline
\end{tabular}

We used Independent Samples T-Test to examine whether there are differences within the dimensions between students from University $U$ and $S$. No differences were found among all dimensions between both universities, within t (252), the $p$ values range from .876 and .105. From this finding, we proceed to the next step by selecting 195 respondents from University $U$. This student group was then made as the base of this study.

Descriptive analysis yielded 2 items with the lowest mean score: (1) an item from the dimension of Social Role, that measures whether the instructors are able to interpret the procedures of instructional design and plan into 1 set of learning activities, learning materials, supporting information and assessment rubric ( $M=3.7$; s.d=.99), and (2) an item from the dimension of Designer/Planner Role, that measures whether the instructors are able manage the online interaction with distance learners through its synchronous activities $(M=3.9$; s.d.= .97). These items were valued as less favourable by the students.

There are 2 items that have the highest mean scores, they are Social Role dimensions which measures whether the instructor are able to: (1) diagnose misconceptions during online discussion ( $M=4.4$; s.d=.60); and (2) communicate in the virtual room $(M=4.3 ;$ s.d.=.61). These two items were valued as the most favourable among other 35 items. 


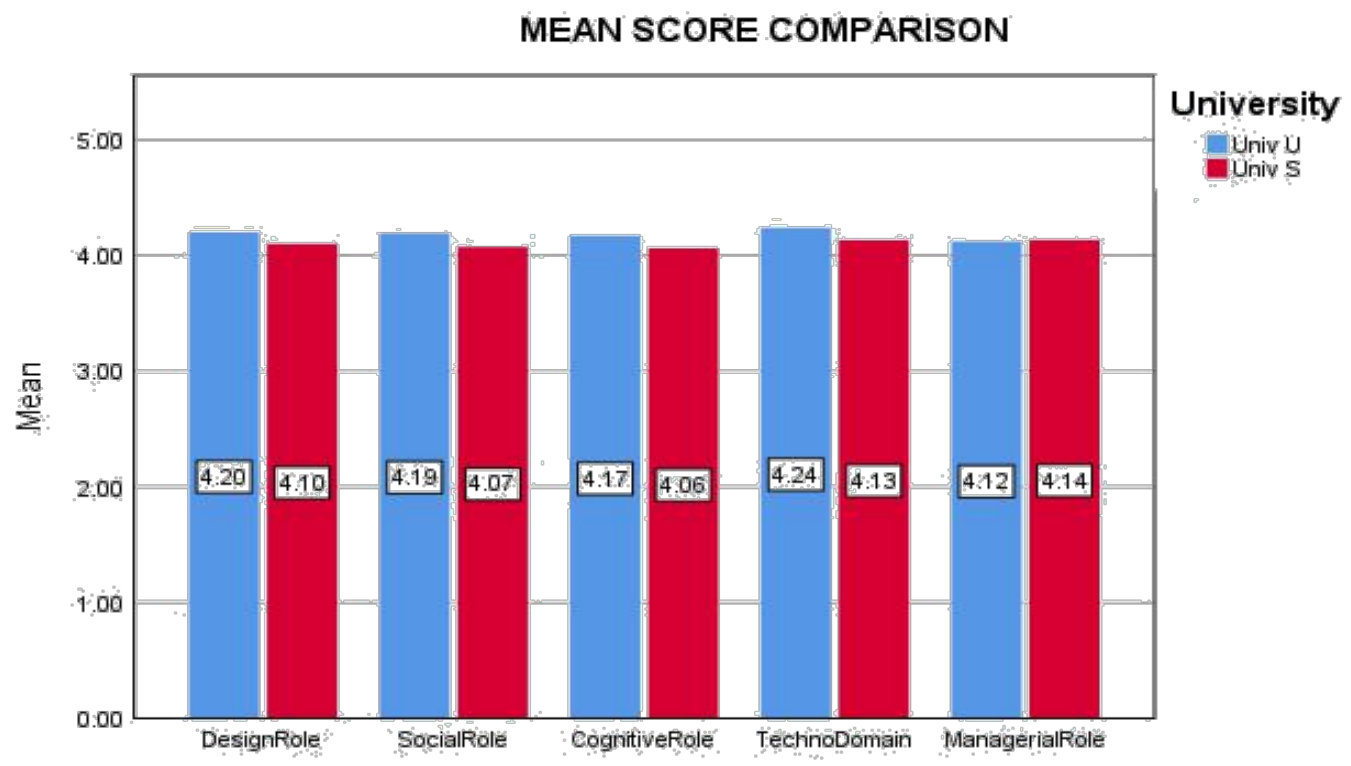

Figure 2 Mean Score Comparison per dimension

In general, we noticed that in average the means score of each dimension from University $S$ is slightly lower than University $U$. This might occur as the respondents from University $S$ are not yet familiar with their specific online learning demands. In addition, the students have not yet formally exposed to online learning environments.

The questionnaire consists of 35 items with 5 dimensions and is found to be highly reliable $(\alpha=.762$ for Designer/Planning Role Dimension, $\alpha=.887$ for Social Role Dimension, $\alpha=.869$ for Cognitive Role, $\alpha=.882$ for Technological Domain, $\alpha=.816$ for Managerial Role).

\section{Factor Analysis}

Factor analysis was applied to extract possible latent factors from the data. It is a data reduction analysis that tries to explain correlations among multiple variables. The result of factor analysis is one or more underlying factors.

Table $5 \mathrm{KMO}$ and Barlett's Test

Kaiser-Meyer-Olkin Measure of Sampling $\quad 0,936$

Adequacy.

Bartlett's Test of Sphericity

\begin{tabular}{|ll} 
Approx. & 3983,618 \\
Chi- & \\
Square & \\
df & 595 \\
Sig. & 0,000
\end{tabular}

The KMO Statistic scored 0.93 which means that the answer patterns correlation is relatively compact, and this factor analysis should yield distinct and reliable factors. 
Table 6 Total Variance Explained

\begin{tabular}{|c|c|c|c|c|c|c|}
\hline \multirow[t]{2}{*}{ Factor } & \multirow{2}{*}{$\begin{array}{l}\text { Initial } \\
\text { Eigenvalues } \\
\text { Total }\end{array}$} & \multirow[b]{2}{*}{$\%$ of Variance } & \multirow[b]{2}{*}{ Cumulative \% } & $\begin{array}{l}\text { Rotation Sums of } \\
\text { Squared Loadings }\end{array}$ & \multirow{2}{*}{ Variance ${ }^{\text {of }}$} & \multirow{2}{*}{$\begin{array}{l}\text { Cumulative } \\
\%\end{array}$} \\
\hline & & & & Total & & \\
\hline 1 & 14,457 & 41,307 & 41,307 & 6,477 & 18,507 & 18,507 \\
\hline 2 & 2,013 & 5,751 & 47,058 & 4,771 & 13,631 & 32,138 \\
\hline 3 & 1,715 & 4,899 & 51,957 & 2,740 & 7,828 & 39,966 \\
\hline 4 & 1,275 & 3,643 & 55,599 & 2,666 & 7,616 & 47,582 \\
\hline 5 & 1,166 & 3,330 & 58,930 & 1,622 & 4,634 & 52,216 \\
\hline
\end{tabular}

The above table shows partly the factors that were extracted. From 35 factors only 5 factors were found to meet the cut-off criterion, with Initial Eigenvalues above 1. Principal Axis Factoring extraction method is applied which aligns with Exploratory Factor Analysis principle, with the assumption that this factor analysis will yield common model of the construct. These 5 factors have percentages of variance of $18.5,13.6,7.8,7.6$, and 4.3 . In total, these 5 factors can explain $52.2 \%$ the variability in all 35 items from the construct of students expectation toward role of instructor in online learning. This cumulative variability is still considered mediocre since the ideal cumulative variance has to be above $70 \%$.

Table 7 Factor Analysis

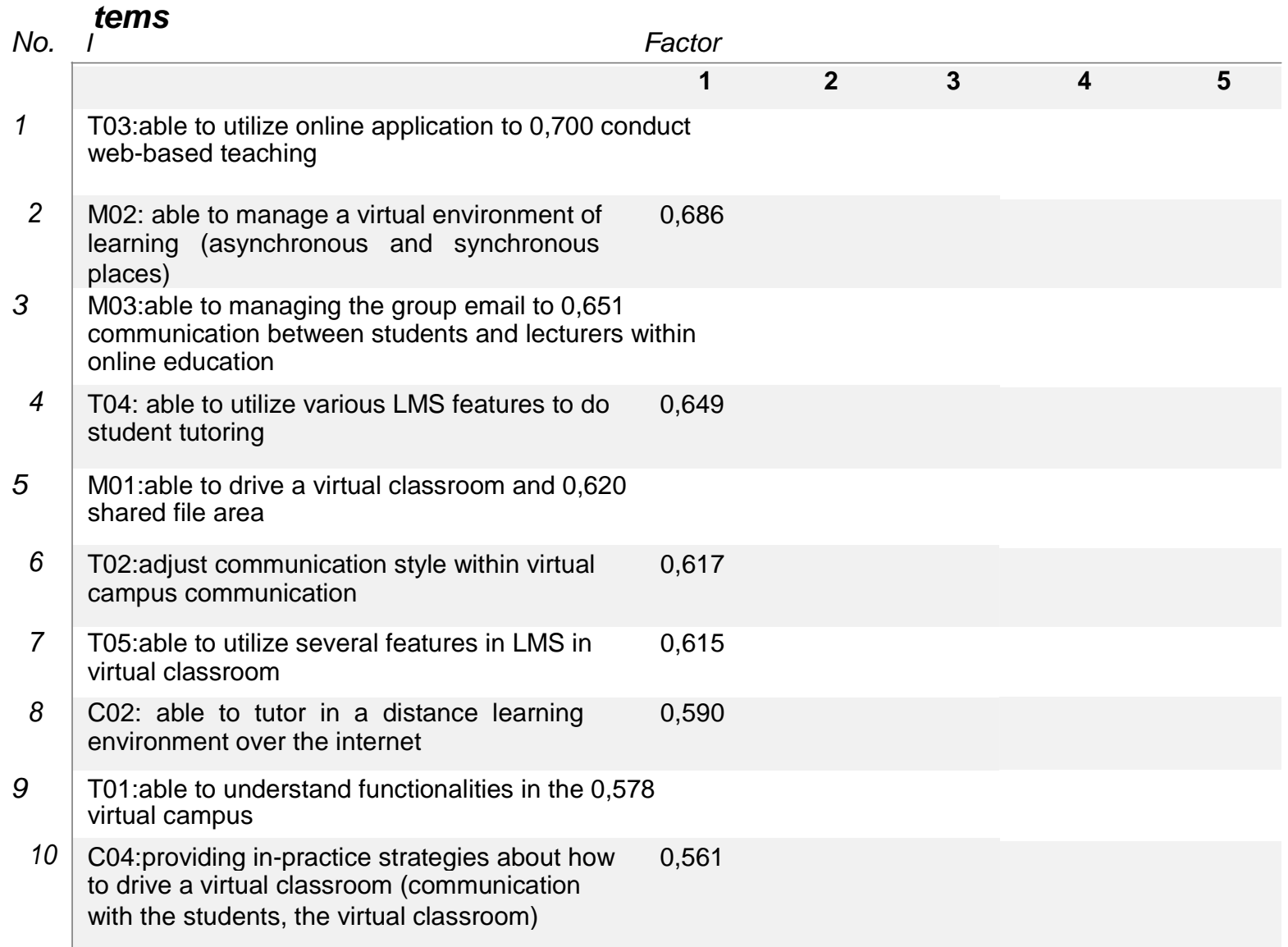


No.

Items

11

M04:able to monitor in the class praxis the delivery of the complementary content in an online format and injecting knowledge from diverse sources (e.g., textbook, articles, internet, personal experience)

12 C05:able to know aspects of collaborative, active, constructive, reflective and authentic learning

13 T07:establishing working with ICT in campus and flexible courses

14 S09:able to start and prompting discussion in online forum

S11: able to confirm understanding through assessment and explanatory feedback

S08:able to engage students to participate in virtual classroom through online discussion

17 S10: able assess the efficacy of the process

18 C03: able to validate student's knowledge acquired through virtual class

19 C07: able to evaluate of their teaching in webbased virtual classroom regularly

20 C06:able to organize online learning activities (live synchronous interaction in virtual classrooms, homework and virtual labs)

21 C01: able to provide learning guidance and evaluation and factors that influence interaction on the virtual class

22 D02:considering the resources and the assessment in a virtual classroom

23 D03:able to provide appropriate learning contents and assignments/tasks in the online class

24 D01:able to interpret the procedures of instructional design and plan into 1 set of learning activities, learning materials, supporting information and assessment rubric

05: able to create of online interactive content

agreement/disagreement during online discussion in the virtual classroom

S05:able to diagnose misconceptions during online discussion

S06: able to seek consensus/understanding, encouraging, acknowledging or reinforcing student contributions

30 S03:able to communicate appropriately in the virtual room

31 S02: able to manage the online interaction with distance learners through its synchronous activities

Extraction Method: Principal Axis Factoring.

Rotation Method: Varimax with Kaiser

Normalization. Rotation converged in 10 iterations.

\section{Factor}

$\begin{array}{lllll}1 & 2 & 3 & 4 & 5\end{array}$

0,541

0,530

0,505

0,773

0,663

0,465 
The above table offers some interesting findings:

Factor 1 are dominated by items from the original theoretical construct dimension of Managerial and Technological domain, followed slightly by cognitive role. These items have strong correlations with factor 1 . Later, it is hypothesized that students expect their instructors to be able to manage the LMS and its features in combination with other ICT tools when delivering online learning scenarios. This initial assumption came up after observing the indicators of the items. Namely, utilizing online applications to conduct web-based learning, utilizing email and shared folder, communicating within LMS, applying teaching strategy within virtual classroom, and applying collaborative interaction with regard of communicating within virtual classroom.

Factor 2 are dominated by items from the original theoretical construct dimension Social and Cognitive Role. This comes off as quite interesting, as we could initially hypothesize that students expect that the role of teacher in online learning would be a combination of communication and cognitive elements. Thus, observing the dominant factor loading of the items, we hypothesized that students expect that their teachers are able to moderate online discussion, providing appropriate feedbacks, confirming student understanding, assessing efficacy of students during online discussion, validating of student's knowledge acquisition and evaluating teacher strategies in virtual classroom.

Factor 3 are dominated by items from the original theoretical construct dimension of designer/planner role only. Observing the items, we could assume that students expect their teachers as being able to consider learning resources and assessments, selecting appropriate learning resources, interpreting and applying their instruction strategies into a set of online learning activities and being able to create interactive learning contents. In the original theoretical construct there is one item which has been removed in this analysis which is the setting time parameter in online learning. We understand that from this analysis students might not consider setting time parameter in online learning as part of an instructor role. It is further hypothesized that these students are used to or do not expect a strict timing online learning schedule. This should be further analysed in relation with self-regulation learning or self-study learning strategy.

Factor 4 are dominated by items from the original theoretical construct dimension of partly Social role only. In this observation, the original construct dimension of Social Role has been divided into 2 parts of latent factors: factor 2 which combine part of Social and Cognitive Role, and Factor 4 which may reflect purely Social Role of the instructor in online learning. Within this factor, there are items that student indicated they expect teacher get involved to online discussion by means of detecting disagreement and diagnosing misconceptions, and also facilitating students to make consensus, encouraging, acknowledging or reinforcing student contributions in 
online discussion. This also offers an interesting perspective of what students expect from their instructors.

Factor 5 contains only 1 item from Social Role dimension that measurse the student expectation toward instructor role in managing online learning with synchronous communication. Applying the statistical assumption of factor analysis, this latent factor could be ignored because we aimed to reduce the dimensionality of the original theoretical construct and also to provide interpretation of a more relevant construct dimension (Rietveld \& Van Hout 1993: 254).

In total, there are 5 items that have been removed from Table 7 due to the factor loading that values less than .4 , which meas they have less significant correlations

to any of the 5 latent factors. These items measured student expectation towards the ability of the instructor to write and present sequenced instructional material, translating learning materials into interactive activities, setting learning time parameter, and setting learning climate in online learning scenarios.

\section{DISCUSSION}

The total sample that has been used to conduct the analysis may be limited. However by observing the students' background data, we could point out some interesting findings and may potentially model the students' expectation toward their instructors' role in online learning environment. These 195 students have been exposed to different scenarios of online learning such as distance learning programs which has about $80 \%$ components of fully online self-study learning, and also blended/hybrid learning that utilized Learning Management System (LMS) as the supplementary to the traditional face-to-face learning.

As mentioned earlier in the literature review, our students who fall into category of Millennials generation prefer to a learning environment that utilize technology where they can measure progress and achieve goals (Jones-Dwyer and Pospisil 2005; Sweeney 2006). As our respondents are mostly characterized by millennial generation, it is then makes more sense that in the first latent factor, there are items with high factor loading which indicates a combination of managerial and technological domain. They expect the instructor to be able to utilize available technology, combining managerial role and understanding toward available technology to create a meaningful learning space where students can check their learning progress and achieve goals. The understanding on how to use the features in LMS and in combination with available communication tools such as email, group email, synchronous and asynchronous communication tools are crucial to create a flexible online course.

Beyond the millennial generation characteristic, it is indicated from the second latent factor that instructor's communication skills do not simply stand for influencing 
students' relationships with the instructor and with other students only. We also found that these communication skills should be combined with an understanding on how to stimulate students cognitively. Instructors need to develop communication skills which stimulate student cognition during online learning with strong emphasis on the collaborative demand among students. Thus, we consider this as an important finding, closely related to the $21^{\text {st }}$ century skills demand. Our students might feel that they need to develop creativity, self-motivation, innovation, problem-solving and collaboration skills along with the course of learning, as mentioned by Barber \& King (2016).

In terms of the Social role expectation, it is mostly aimed to manage communication, Lasly, Mupinga, Nora, Yaw (2006) also mentioned that a frequent communication with the instructor makes student knows that they are not missing any important points and be present virtually in online learning. The fourth latent factor found consists of items from Social Role that have high factor loading measuring student expectation toward the instructor to detect disagreement and to diagnose misconceptions, and also to facilitate students to make consensus, encouraging, acknowledging or reinforcing student contributions in online discussion.

Student still expect regular contact and instant email or via web-based communication. There is also a tendency that students expect their instructor to be "available" 24 hours to confirm that their assignments have been successfully submitted. This is also related to the habit of millennial generations who always wish to stay connected.

Designing or planning the online learning environment is the third latent factors in this finding. Most of the items that have high factor loading indicated that students' expectation are going toward how well the instructors translate traditional learning material into interactive content and also meaningful assessment. Students tend to expect a flexible course planner and more independent learning trajectory.

Summarizing this discussion section, we reckon that our findings have promoted further support to the TPACK framework in online learning environment. The overlap of Technological Pedagogical Knowledge (TPK) - An understanding of how teaching and learning can change when particular technologies are used in particular ways, is very crucial. Reflecting from the students expectation, instructor in online learning must know the pedagogical affordances and constraints of a range of technological tools as they relate to disciplinarily and developmentally appropriate pedagogical designs and strategies" (Koehler \& Mishra, 2009).

As Chung et al. (2016) mentioned, Millennial students require their instructors to be innovative. This signifies that instructor must understand not only the subject or content they teach but also how to utilize the available technology as part of teaching in online learning environment. Hence, in order to play the role as effective instructor, 
lecturers must master skills on how to manage and utilize technology and communicating effectively, creating engaging learning materials, and planning learning activities.

\section{CONCLUSION AND SUGGESTION}

Due to limited number of respondents, we concluded that the 4 latent factors found in this study require further analysis. In spite of the limitation, the findings might in fact suggest a new theoretical construct dimensions that closely model the student expectation toward instructor role in online learning environment. We propose new dimensions under the names as follow: (1) Techno-Pedagogy domain: emphasizing instructors role that is intelligent, planful, creative, tech-savvy and passionate to the student's learning needs and have a calculated risk when applying instructional design in technological environment; (2) Socio-cognitive role: emphasizing collaborative learning strategy within the technological learning environment, including managing modern communication tools and learning resource sharing to gain effective knowledge construction; (3) Instructional Plan role: emphasizing the competence of the instructor to come up with interactive learning material and activities, and determining meaningful assessment tools and strategy; and (4) Engagement Role: emphasizing the instructors' competence to apply their communication skills to continuously engage with the student by available communication channels.

Understanding the student' expectation toward instructor role in online learning environment is seen as prospective to increase the learning satisfaction and producing learning outcomes. Educational institutions that aim to implement online learning must consider the actual interaction of instructor competence and skills and student's expectation in teaching and learning processes. Hence, they must plan the professional development of instructor and tutor for online learning seriously and carefully. As a starting point, any education institution could apply these findings as the required competence profile of the instructor and tutor. As a competence profile, each education institution could verify it at the later stage of online learning implementation by finding the accordance of students' expectation and instructors' behaviour in online learning environment. It is advised to monitor and analyze the student and instructors behaviour in online learning environment by applying learning analytic tools.

Further study shall be conducted to model this construct of student expectation toward instructor role in online learning environment, by taking a wider data collection in different higher education institutions. 


\section{REFERENCES}

Alexander, A. (2012). Understanding and meeting the needs of the millennials in the classroom: A literature review.

Barber, W., \& King, S. (2016). Teacher-Student Perspectives of Invisible Pedagogy: New Directions in Online Problem-Based Learning Environments, 14(4), 235- 243.

Benson, S. N. K., \& Ward, C. L. (2013). Teaching with Technology: Using Tpack to Understand Teaching Expertise in Online Higher Education. Journal of Educational Computing Research, 48(2), 153-172. https://doi.org/10.2190/EC.48.2.c

Chu, S. K. W., Reynolds, R. B., Tavares, N. J., Notari, M., \& Lee, C. W. Y. (2016). 21st century skills development through inquiry-based learning: From theory to practice. 21st Century Skills Development Through Inquiry-Based Learning: From Theory to Practice, 1-204. https://doi.org/10.1007/978-981-10-2481-8

Dabbagh, N., \& Kitsantas, A. (2012). Personal Learning Environments, social media, and self-regulated learning: A natural formula for connecting formal and informal learning. Internet and Higher Education, 15(1), 3-8. https://doi.org/10.1016/j.iheduc.2011.06.002

Ghazal, S., Aldowah, H., Umar, I., \& Bervell, B. (2018). Acceptance and Satisfaction of Learning Management System Enabled Blended Learning Based on a Modified DeLone-McLean Information System Success Model. International Journal of Information Technology Project Management, 9(3), 5271. https://doi.org/10.4018/IJITPM.2018070104

Gilbert, B. (2015). Online Learning Revealing the Benefits and Challenges. Retrieved from http://fisherpub.sjfc.edu/education_ETD_masters

Gómez-Rey, P., Barbera, E., \& Fernández-Navarro, F. (2018). Students' perceptions about online teaching effectiveness: A bottom-up approach for identifying online instructors' roles. Australasian Journal of Educational Technology, 34(1), 116130. https://doi.org/10.14742/ajet.3437

Henry, M. (2018). The online student experience: An exploration of firstyear university students' expectations, experiences and outcomes of onlineeducation. Retrieved from https://ro.ecu.edu.au/theses/2059 
Koehler, M. J., \& Mishra, P. (2009). What is technological pedagogical content knowledge? Contemporary Issues in Technology and Teacher Education, 9(1), 60-70.

Mncube, L. S., Dube, L., \& Ngulube, P. (2017). The Role of Lecturers and University Administrators in Promoting New E-Learning Initiatives. International Journal of Virtual and Personal Learning Environments, 7(1), 1-11. https://doi.org/10.4018//JVPLE.2017010101

Partnership for 21st century skills. (2011). Learning and Innovation Skills - 4Cs Framework for 21st Century Learning The Partnership for 21st Century Skills has developed a vision for student success in the new global economy, 2. Retrieved from http://www.p21.org/storage/documents/1._p21_framework_2-pa Purbojo R. (2018) Role of the University Lecturer in an Online Learning Environment: An Analysis of Moodle Features Utilized in a Blended Learning Strategy. In: Persichitte K., Suparman A., Spector M. (eds) Educational Technology to Improve Quality and Access on a Global Scale. Educational Communications and Technology: Issues and Innovations. Springer, Chamger.pdf

Richardson, J. C., Besser, E., Koehler, A., Lim, J. E., \& Strait, M. (2016). Instructors' perceptions of instructor presence in online learning environments. International Review of Research in Open and Distance Learning, 17(4), 82-104. https://doi.org/10.19173/irrodl.v17i4.2330

Rietveld, T. \& Van Hout, R. (1993). Statistical Techniques for the Study of Language and Language Behaviour. Berlin - New York: Mouton de Gruyter.

Rodriguez, M., \& Honeycutt, E. (2014). Using technology to engage and improve millennial students' presentation performance. Atlantic Marketing Journal, 3(2), 16-32. Retrieved from http://digitalcommons.kennesaw.edu/amj/vol3/iss2/3/

Systems, S. (2016). P21 Framework for 21st Century Learning 21st Century Student Outcomes and Support Systems Framework for 21st Century Learning. https://doi.org/10.2307/3588214

The Partnership For 21St Century Skills. (2009). 21st CENTURY STUDENT OUTCOMES. Framework, 1-9. https://doi.org/10.1016/S0006-291X(02)00578-8 


\section{ABOUT THE AUTHORS}

Rijanto Purbojo: Faculty Member of Master of Education and Manager of Education Technology, Universitas Pelita Harapan, Lippo Village - Tangerang, Banten Province, Indonesia

Gemala Garibaldi: Professional Trainer and Faculty member of Business Administration - Hotel and Tourism Management Study, Swiss German University University, Alam Sutra - Tangerang, Indonesia. 